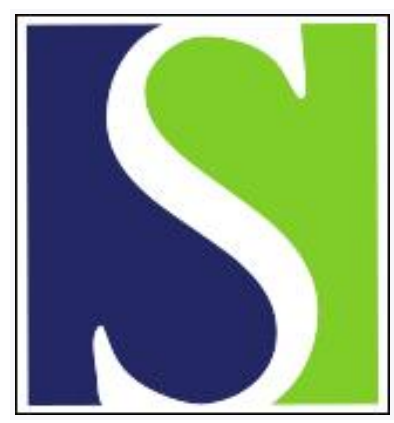

Scand J Work Environ Health 2002;28(6):394-401

https://doi.org/10.5271/sjweh.691

Issue date: Dec 2002

Work-schedule characteristics and reported musculoskeletal disorders of registered nurses

by Lipscomb JA, Trinkoff AM, Geiger-Brown J, Brady B

Affiliation: Department of Behavioral and Community Health, University of Maryland School of Nursing, 655 W Lombard Street, Baltimore, MD 21201-1579, United States. lipscomb@son.umaryland.edu

Refers to the following texts of the Journal: 1998;24(5):367-375 1998;24 suppl 3:62-68 1998;24 suppl 3:49-54 1998;24 suppl 3:43-48 1998;24 suppl 3:69-75

The following articles refer to this text: $2014 ; 40(4): 400-410$; 2020;46(2):152-160

Key terms: back problems; long workhours; MSD; musculoskeletal disorder; neck problem; registered nurse; shift work; shoulder problem; work-schedule characteristics

This article in PubMed: www.ncbi.nlm.nih.gov/pubmed/12539799 


\title{
Work-schedule characteristics and reported musculoskeletal disorders of registered nurses
}

\author{
by Jane A Lipscomb, PhD, ${ }^{1}$ Alison M Trinkoff, ScD, ${ }^{1}$ Jeanne Geiger-Brown, PhD, ${ }^{1}$ Barbara Brady, MS ${ }^{1}$
}

\begin{abstract}
Lipscomb JA, Trinkoff AM, Geiger-Brown J, Brady B. Work-schedule characteristics and reported musculoskeletal disorders of registered nurses. Scand J Work Environ Health 2002;28(6):394-401.
\end{abstract}

Objectives The relationship between a combination of demanding work-schedule characteristics and reported musculoskeletal disorders of the neck, shoulders, and back was examined.

Methods A probability sample of 1163 nurses, randomly selected from the list of actively licensed nurses in two states of the United States, served as the sample for this cross-sectional study. Data were collected via an anonymous survey mailed to the participants' homes from October 1999 through February 2000.

Results Four of the nine work-schedule characteristics (working full-time, $>8$ hours/day, 2-4 weekends/ month, and other than day shift) were significantly related to musculoskeletal disorders in one or more body sites. When a work-schedule index was created by summing the nine characteristics, a demanding schedule was significantly associated with musculoskeletal disorders in the neck [odds ratio (OR) 1.10, 95\% confidence interval (95\% CI) 1.00-1.21], shoulder (OR 1.12, 95\% CI 1.01-1.23), and back (OR 1.16, 95\% CI 1.06-1.27). Adjustment for psychological and physical job demands reduced the odds ratios slightly and therefore suggested that some of the association between musculoskeletal disorders and schedule was due to increased exposure to these job demands. Working "long hours" ( $>12$ hours/day, $>40$ hours/week) and "off hours" (weekends and "other than day shifts") were associated with a 50-170\% increase in the age-adjusted odds ratio for musculoskeletal disorders in the three body sites.

Conclusions The findings of this study suggest that preventing musculoskeletal disorders requires systemlevel approaches to scheduling that reduce the time of exposure to demanding work conditions and promote healthful work-rest patterns.

Key terms back problems, long workhours, neck problems, shift work, shoulder problems.

Patient care demands 24 hours/day, 7 days/week nursing coverage in hospitals and many other health care settings. In order to meet these demands, nurses have historically been required to work a variety of schedules. Sweeping changes in the health care industry in the United States over the past two decades have led to an increase in extended and highly demanding work schedules (1-3). The impact of extended work schedules on nurses' health and safety is of concern because such schedules increase exposure to physical and psychological job demands and reduce time for rest and recuperative leisure-time activities.

Nurses face many occupational health problems, the most common being musculoskeletal disorders. Among all nonfatal injuries recordable by the Occupational
Safety and Health Administration (OSHA) in the United States, nursing and personal care facilities rank second (incidence rate 13.8/100) among all industries and hospitals rank sixth (8.4/100) (4). The high prevalence of musculoskeletal disorders among nurses is thought to be due to the physical demands of the work, as well as to work organizational factors, of which scheduling is an important component (5-12). As nurses are already at high risk for musculoskeletal problems, the increasing use of extended work schedules is likely to lead to increased exposure to demands and even higher rates of injury.

Research on the impact of work scheduling on health care workers has largely focused on shift work and, to a less extent, on workshift duration (13-26). Gold et al

1 Department of Behavioral and Community Health, University of Maryland School of Nursing, Baltimore, Maryland, United States.

Correspondence to: Jane A Lipscomb, Department of Behavioral and Community Health, University of Maryland School of Nursing, 655 W Lombard Street, Baltimore, MD 21201-1579, USA. [E-mail: lipscomb@ son.umaryland.edu] 
found that nurses working rotating shifts had twice the number of reported accidents or errors related to sleepiness than nurses who worked only a day or evening shift (14). Danish nurses working rotating shifts were found to have significantly more clinic visits related to sprains and strains than nurses working other shifts (18). Other studies have investigated health outcomes associated with nursing shift work, although the focus has largely been on gastrointestinal, mental, and cardiovascular disorders (19-21, 27).

Working 12 or more hours has been shown to increase exposure to physical demands and reduce recovery time between workshifts, potentially resulting in increased musculoskeletal disorders $(22-23,28)$. Engkvist et al (24) found that Swedish nurses working over 35 hours a week were at increased risk of back injury [odds ratio (OR) 2.4, 95\% confidence interval $(95 \% \mathrm{CI})$ 1.6-3.6]. Back and leg complaints were found to be associated positively with hours worked per week among nursing home staff in The Netherlands (25).

The report of the Institute of Medicine (IOM) on nurse staffing (26) cited the paucity of studies into the impact of extended work schedules on the health and safety of health care workers and called for research in this area. Such study is particularly critical given the increasing exposure of health care workers and others to extended schedules. Furthermore, the combined effect of shifts and hours, along with other such factors, such as weekend work, overtime, and work breaks, have not been investigated.

We therefore undertook this exploratory study to examine the relationship between a combination of demanding work-schedule characteristics and reported neck, shoulder, and back musculoskeletal disorders among nurses. The examination of the association between factors related to work schedules and musculoskeletal disorders may lead to schedule modifications that improve the health and safety of health care workers.

\section{Material and methods}

\section{Sample and data collection}

Two states in the United States were chosen for the sample, Illinois and New York. In each state, 1000 nurses were randomly selected from the list of actively licensed nurses residing in that state, for a total sample population of 2000. Among the 1428 (74\%) who responded to the survey, the 1163 who were currently working in nursing served as the sample for this analysis. Data were collected via an anonymous survey mailed to the participants' homes from October 1999 through February 2000. The instrument was an 8-page questionnaire

which had been designed for optical scanning and contained sections on neck, shoulder and back problems, workplace, position, physical demands, psychological demands, and work-schedule characteristics. Participant contact was attempted through up to six first-class mailings, three including the questionnaire and three being a reminder postcard. The final contact used certified mailing to deliver the questionnaire.

Table 1 provides a description of the sample, including the proportion of nurses who reported selected workschedule demands. Demographically, the sample was typical of nurses in the United States (29). This group of nurses worked an average of 8.9 hours a day, and $65 \%$ of them reported taking no more than one break (including meal breaks) during their workday.

\section{Variable definitions}

Musculoskeletal problems were ascertained by inquiring about symptoms in the neck, shoulders and back, including pain, numbness, tingling, aching, stiffness, and burning in the past year, as adapted from the Nordic Questionnaire of Musculoskeletal Symptoms (30). A reported case of a musculoskeletal disorder was defined as a relevant symptom with a duration of at least 1 week, or occurring at least monthly in the past year; with a pain intensity of at least 3 (moderate) on a 5-point pain scale (31). In addition to meeting these criteria, the respondent had to have worked in his or her current nursing job for at least one year and could not have sustained a nonwork-related injury or accident up to 3 months

Table1. Description of the sample, , $^{\mathrm{a}, \mathrm{b}}$ including selected workschedule characteristics, for working nurses with $\geq 1$ years in their current job, 1999-2000 ( $\mathrm{N}=1163)$.

\begin{tabular}{lrr}
\hline Attribute & $\mathrm{N}$ & $\%$ \\
\hline Demographics & & \\
Gender (female) & 1091 & 95.4 \\
Race (white) & 950 & 83.0 \\
Ethnicity (Hispanic or Latino) & 32 & 2.8 \\
Marital status (married) & 769 & 71.0 \\
Educational attainment (bachelor or higher degree) & 579 & 50.3 \\
Work characteristics and scheduling & & \\
Current primary nursing position (staff nurse) & 761 & 67.4 \\
Type of primary workplace (hospital) & 660 & 57.5 \\
Full-time & 810 & 69.6 \\
One job & 980 & 84.3 \\
Working $\geq 5$ days/week & 1084 & 94 \\
Weekends/month ( $\geq 2$ ) & 572 & 50.0 \\
Day shift & 883 & 75.9 \\
Breaks of $\geq 10$ minutes (0-1 breaks) & 744 & 65.0 \\
Breaks away from unit (never/rare) & 744 & 64.8 \\
\hline a Mean age: 45.0 (SD 10.2) years. & & \\
' Mean time worked/day 8.9 (SD 2.0) hours; mean time worked/week: \\
37.9 (SD 12.4) hours.
\end{tabular}


prior to the onset of the musculoskeletal symptoms. Nurses reporting no neck, shoulder or back problems were coded as asymptomatic.

The work-schedule characteristics were measured through the use of nine variables addressing days worked, length of day, and work breaks. The results were then summed to form an index of demanding workschedule characteristics. The categories for each variable defined as demanding included full-time work (versus part-time), more than one job, more than 8 hours of work per day, more than 40 hours of work per week, 6 or 7 days of work a week, work on two or more weekends a month, workshifts other than days, no more than one break lasting 10 minutes or more per shift, and never or rarely breaks out of the unit. One point was given for each of the nine demanding schedule items, and an extra point each was given for extreme hours per day $(\geq 12$ hours) and per week ( $\geq 50$ hours), resulting in a possible score of 0-11 points.

\section{Potential explanatory variables}

In addition to scheduling characteristics, demographic and work variables that may explain an association between schedule and musculoskeletal disorders, if present, were determined. They included age (continuous), ethnicity, children under 4 years of age, and care for older children or other dependents. Workplace and position were dichotomized as hospital versus other and staff nurse versus other, respectively.

Psychological demands were measured using eight items from the Job Control Questionnaire (32). Each item (eg, work hard, work fast) was measured on a 4point scale to indicate the frequency of exposure. Responses were dichotomized and summed, generating total scores ranging from 0 to 8 for a continuous psychological demand scale (alpha 0.78).

Exposure to physical demands, such as awkward postures, heavy lifting, and pushing and pulling heavy loads, was measured by 12 items (31-35). As with the psychological demand scale, each item was measured on a 4-point scale, with the responses dichotomized and summed, to generate total scores ranging from 0 to 12 for a continuous physical demand scale (alpha 0.89).

\section{Data analysis}

The descriptive analysis of the data included the prevalence of work-schedule characteristics and cross-tabulations of each by musculoskeletal disorders of the neck, a shoulder, and the back. The mean level of work-schedule demands was estimated for the cases of musculoskeletal disorders and for the nurses who were completely asymptomatic, along with estimates of the odds of having a musculoskeletal disorder (neck, shoulder, and back) in relation to each individual work-schedule characteristic.

Logistic regression models were generated using the continuous work-schedule index for each body site to detect the additive influence of each additional characteristic on the likelihood of having a musculoskeletal disorder. The odds ratios for each outcome were adjusted for all potential explanatory or confounding factors in blocks in the following order: demographics, workplace and position, psychological demands, and finally physical demands. These analyses were conducted for the total group of nurses, and also for subgroups of staff nurses only and hospital nurses only.

A principal component analysis was performed on the work-schedule items to identify underlying patterns for the scheduling components. We used a forced fourfactor solution based on our theoretical formulation of how these items would cluster and subjected the output to Varimax rotation. The factors were designated as, "off shifts", "days worked", "hours worked", and " work breaks". For each of the four factors, we constructed a hierarchy such that the reference condition included the lowest risk category from each variable. Then plausible categories of risk were created by combining levels of each variable, the highest risk category of each variable together forming the high-risk category of the constructed hierarchy. Although full-time work loaded on the "hours worked" factor, we excluded it from the constructed hierarchy because it added no conceptual benefit. The relationship of each factor to musculoskeletal disorders was then estimated for each body site, and crude and age-adjusted odds ratios were generated.

\section{Results}

The prevalence of reported cases of musculoskeletal disorders in the neck, a shoulder, or the back in this study was $20 \%, 17 \%$ and $29 \%$, respectively. When analyzed individually, four of the nine work-schedule characteristics were significantly related to reported musculoskeletal disorders in one or more body sites (table 2). Other than dayshift work was significantly associated with shoulder and back disorders. Full-time work (versus part-time), $\geq 12$ hours of work per day, $>40$ hours of work per week, and work on $\geq 2$ weekends per month were each associated with musculoskeletal disorders in the back. When the nine items were summed, the mean score for the asymptomatic nurses was 3.82 demanding work-schedule characteristics, compared with a mean of 4.17 (95\% CI 3.88-4.45), 4.16 (95\% CI 3.85-4.47), and 4.35 (95\% CI 4.12-4.59) for the nurses with neck, shoulder, or and back disorders, respectively. 
Table 2. Age-adjusted odds ratios (OR) for reported cases of musculoskeletal disorders by work-schedule characteristic, for working nurses ${ }^{\text {a }}$ with $\geq 1$ years in their current job, 1999-2000. (95\% Cl = 95\% confidence interval)

\begin{tabular}{|c|c|c|c|c|c|c|}
\hline \multirow[t]{3}{*}{ Work-schedule variables } & \multicolumn{6}{|c|}{ Musculoskeletal disorder } \\
\hline & \multicolumn{2}{|c|}{$\operatorname{Neck}^{a}(\mathrm{~N}=229)$} & \multicolumn{2}{|c|}{ Shoulder $^{\mathrm{a}} \quad(\mathrm{N}=192)$} & \multicolumn{2}{|c|}{$\operatorname{Back}^{\mathrm{a}}(\mathrm{N}=298)$} \\
\hline & $\mathrm{OR}$ & $95 \% \mathrm{Cl}$ & $\mathrm{OR}$ & $95 \% \mathrm{Cl}$ & $\mathrm{OR}$ & $95 \% \mathrm{Cl}$ \\
\hline \multicolumn{7}{|l|}{ Status } \\
\hline $\begin{array}{l}\text { Part-time } \\
\text { Full-time }\end{array}$ & $\begin{array}{l}1.00 \\
1.48\end{array}$ & $\begin{array}{c}\ddot{.} \\
0.99-2.21\end{array}$ & $\begin{array}{l}1.00 \\
1.28\end{array}$ & $\begin{array}{c}\ddot{0} \\
0.84-1.95\end{array}$ & $\begin{array}{l}1.00 \\
1.92\end{array}$ & $\begin{array}{c}\ddot{1.30-2.84}\end{array}$ \\
\hline \multicolumn{7}{|l|}{ Number of jobs } \\
\hline $\begin{array}{l}\text { One } \\
\text { Two }\end{array}$ & $\begin{array}{l}1.00 \\
1.37\end{array}$ & $\begin{array}{c}\ddot{.} \\
0.86-2.17\end{array}$ & $\begin{array}{l}1.00 \\
1.29\end{array}$ & $\begin{array}{c}\ddot{.} \\
0.78-2.13\end{array}$ & $\begin{array}{l}1.00 \\
1.22\end{array}$ & $\begin{array}{c}\ddot{.} \\
0.79-1.89\end{array}$ \\
\hline \multicolumn{7}{|l|}{ Hours/day } \\
\hline $\begin{array}{l}\leq 8 \\
9-11 \\
\geq 12\end{array}$ & $\begin{array}{l}1.00 \\
1.35 \\
1.22\end{array}$ & $\begin{array}{c}. . \\
0.87-2.09 \\
0.76-1.97\end{array}$ & $\begin{array}{l}1.00 \\
1.14 \\
1.42\end{array}$ & $\begin{array}{c}. . \\
0.70-1.84 \\
0.86-2.34\end{array}$ & $\begin{array}{l}1.00 \\
1.03 \\
1.61\end{array}$ & $\begin{array}{c}. . \\
0.67-1.59 \\
1.05-2.48\end{array}$ \\
\hline \multicolumn{7}{|l|}{ Hours/week } \\
\hline $\begin{array}{l}\leq 40 \\
41-49 \\
\geq 50\end{array}$ & $\begin{array}{l}1.00 \\
1.47 \\
1.11\end{array}$ & $\begin{array}{c}\ddot{*} \\
0.91-2.38 \\
0.69-1.80\end{array}$ & $\begin{array}{l}1.00 \\
1.28 \\
1.10\end{array}$ & $\begin{array}{c}. . \\
0.76-2.16 \\
0.66-1.83\end{array}$ & $\begin{array}{l}1.00 \\
1.50 \\
1.06\end{array}$ & $\begin{array}{c}. . \\
0.96-2.36 \\
0.68-1.67\end{array}$ \\
\hline \multicolumn{7}{|l|}{ Days/week } \\
\hline $\begin{array}{l}1-5 \\
6-7\end{array}$ & $\begin{array}{l}1.00 \\
1.19\end{array}$ & $0.61-2.33$ & $\begin{array}{l}1.00 \\
1.00\end{array}$ & $\begin{array}{c}\ddot{*} \\
0.47-2.10\end{array}$ & $\begin{array}{l}1.00 \\
0.88\end{array}$ & $\begin{array}{c}\ddot{*} \\
0.45-1.72\end{array}$ \\
\hline \multicolumn{7}{|l|}{ Weekends/month } \\
\hline $\begin{array}{l}0-1 \\
2-4\end{array}$ & $\begin{array}{l}1.00 \\
1.34\end{array}$ & $\begin{array}{c}. \ddot{ } \\
0.95-1.90\end{array}$ & $\begin{array}{l}1.00 \\
1.21\end{array}$ & $\begin{array}{c}. \ddot{ } \\
0.84-1.75\end{array}$ & $\begin{array}{l}1.00 \\
1.78\end{array}$ & $\begin{array}{c}. . \\
1.28-2.47\end{array}$ \\
\hline \multicolumn{7}{|l|}{ Shift } \\
\hline $\begin{array}{l}\text { Days only } \\
\text { Other than days }\end{array}$ & $\begin{array}{l}1.00 \\
1.24\end{array}$ & $\begin{array}{c}. \ddot{7} \\
0.87-1.78\end{array}$ & $\begin{array}{l}1.00 \\
1.48\end{array}$ & $\begin{array}{c}. . \\
1.02-2.15\end{array}$ & $\begin{array}{l}1.00 \\
1.49\end{array}$ & $\begin{array}{c}. . \\
1.07-2.08\end{array}$ \\
\hline \multicolumn{7}{|l|}{ Breaks/day } \\
\hline $\begin{array}{l}\geq 2 \\
0-1\end{array}$ & $\begin{array}{l}1.00 \\
1.10\end{array}$ & $\begin{array}{c}\ddot{*} \\
0.76-1.57\end{array}$ & $\begin{array}{l}1.00 \\
1.24\end{array}$ & 0.84-1.83 & $\begin{array}{l}1.00 \\
0.97\end{array}$ & $\begin{array}{c}. . \\
0.69-1.35\end{array}$ \\
\hline \multicolumn{7}{|l|}{ Breaks } \\
\hline $\begin{array}{l}\text { Off unit } \\
\text { On unit }\end{array}$ & $\begin{array}{l}1.00 \\
1.01\end{array}$ & $\begin{array}{c}. . \\
0.71-1.45\end{array}$ & $\begin{array}{l}1.00 \\
1.32\end{array}$ & $\begin{array}{c}. . \\
0.89-1.95\end{array}$ & $\begin{array}{l}1.00 \\
1.20\end{array}$ & $\begin{array}{c}. . \\
0.85-1.67\end{array}$ \\
\hline
\end{tabular}

a Reference $=$ respondents who were completely asymptomatic in all body parts $(\mathrm{N}=320)$.

Work schedule, as measured by the continuous index, was significantly associated with musculoskeletal disorders in the neck (OR 1.10, 95\% CI 1.00-1.21), a shoulder (OR 1.12, 95\% CI 1.01-1.23), and the back $(\mathrm{OR}=1.16,95 \% \mathrm{CI} 1.06-1.27)$. This finding indicates that, with each additional demanding work-schedule component, the likelihood of a musculoskeletal disorder increased by $10-16 \%$, depending on the body site. Once the models were adjusted for psychological and physical demands, the odds ratios remained elevated but were no longer significant, except for musculoskeletal disorders in a shoulder (table 3 ). This finding suggests that the relationship between work schedule and musculoskeletal disorders was in part due to the increased exposure to psychological (full model adjusted OR 1.00-1.06) and physical (full model adjusted OR 1.181.23) demands. Despite this result, after control for all the covariates, on the average, a nurse with a musculoskeletal disorder of the back in this study could attribute a $44 \%$ increase to the odds ratios of a musculoskeletal disorder (ie, $10 \%$ increase in risk of back in- jury $\times 4.35$ demanding schedule characteristics) to their work schedule, independently of psychological and physical work demands.

The principal component analysis of the nine-item work-schedule index, in which eigenvalues $>1$ were retained, with varimax rotation with a four-factor solution, exhibited results as shown in table 4 . When the four factors, "off shifts", "days worked", "hours worked", and "work breaks" were entered into separate logistic regression models, only "off shifts" and "hours worked" were associated with musculoskeletal disorders. Working "off shifts" ( $\geq 2$ weekends/month and other than dayshift work) elevated the odds ratios for musculoskeletal disorders of the neck (OR 1.43, 95\% CI 0.94-2.18), a shoulder (OR 1.52, 95\% CI 0.98-2.38), and the back (OR 2.08, 95\% CI 1.35-2.96) (table 5). In this sample, shift work was associated with an increased risk of musculoskeletal disorders (at three body sites) only when combined with weekend work. Figure 1 graphically shows this effect modification for musculoskeletal disorders of the back. Working "long hours" ( $\geq 12$ hours/day and $\geq 40$ 
Table 3. Odd ratios (OR) of reported cases of musculoskeletal disorders by work-schedule index characteristics for working nurses ${ }^{\mathrm{a}}$ with $\geq 1$ years in their current job, 1999-2000. (95\% Cl = 95\% confidence interval)

\begin{tabular}{|c|c|c|c|c|c|c|}
\hline \multirow[t]{3}{*}{ Work-schedule index } & \multicolumn{6}{|c|}{ Musculoskeletal disorder } \\
\hline & \multicolumn{2}{|c|}{$\operatorname{Neck}^{a}(\mathrm{~N}=197)$} & \multicolumn{2}{|c|}{ Shoulder a $(\mathrm{N}=170)$} & \multicolumn{2}{|c|}{$\operatorname{Back}^{a}(N=270)$} \\
\hline & OR & $95 \% \mathrm{Cl}$ & OR & $95 \% \mathrm{Cl}$ & OR & $95 \% \mathrm{Cl}$ \\
\hline Unadjusted model & 1.10 & $1.00-1.21$ & 1.12 & $1.01-1.23$ & 1.16 & $1.06-1.27$ \\
\hline Model adjusted for demographics & 1.16 & $1.05-1.29$ & 1.19 & $1.06-1.33$ & 1.20 & $1.09-1.33$ \\
\hline Model adjusted for all of the above plus workplace and position & 1.17 & $1.05-1.30$ & 1.19 & $1.06-1.34$ & 1.18 & $1.07-1.31$ \\
\hline Model adjusted for all of the above plus psychological demands & 1.10 & $0.98-1.24$ & 1.15 & $1.02-1.30$ & 1.12 & $1.01-1.25$ \\
\hline Model adjusted for all of the above plus physical demands & 1.07 & $0.95-1.20$ & 1.14 & $1.01-1.29$ & 1.10 & $0.98-1.22^{\mathrm{a}}$ \\
\hline
\end{tabular}

a Reference $=$ respondents who were completely asymptomatic in all body sites $(\mathrm{N}=320)$.

Table 4. Factor analysis for the work-schedule index variables ${ }^{a}$ - eigenvalues for working nurses with $\geq 1$ years in their current job, 1999-2000 ( $\mathrm{N}=1163)$.

\begin{tabular}{lrrrr}
\hline Factor & $\begin{array}{l}\text { Off } \\
\text { shifts }\end{array}$ & $\begin{array}{l}\text { Days } \\
\text { worked }\end{array}$ & $\begin{array}{l}\text { Hours } \\
\text { worked }\end{array}$ & $\begin{array}{l}\text { Work } \\
\text { breaks }\end{array}$ \\
\hline Shift & 0.79 & 0.16 & -0.11 &.. \\
Weekends & 0.78 & 0.14 &.. &.. \\
Days/week &.. & 0.79 &.. &.. \\
Number of jobs & 0.16 & 0.71 &.. &.. \\
Full- versus part-time & -0.18 & 0.10 & 0.77 &.. \\
Hours/week &.. & 0.52 & 0.63 &.. \\
Hours/day & 0.50 & -0.20 & 0.61 &.. \\
Number of 10-minute breaks & -0.11 &.. & -0.12 & 0.82 \\
Number of breaks off unit & 0.22 & -0.15 & 0.11 & 0.72 \\
\hline
\end{tabular}

a Rotated component matrix, constrained to four factors using a principal component analysis as the extraction method and Varimax rotation.

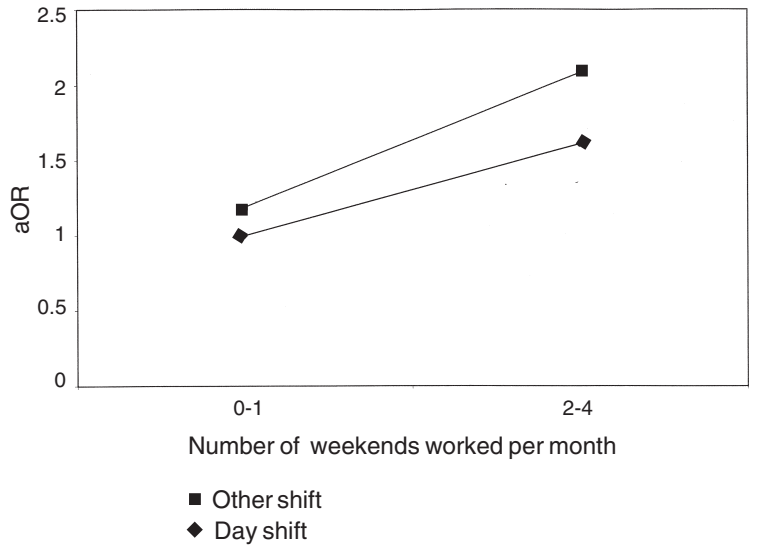

Figure 1. Age-adjusted odds ratios (aOR) for shift by number of weekends worked per month in reported back cases among 1163 registered nurses working $\geq 1$ years in their current job, 1999-2000.

Table 5. Age-adjusted odds ratios (OR) of reported cases of musculoskeletal disorders by work-schedule characteristics for working nurses with $\geq 1$ years in their current job, 1999-2000.

\begin{tabular}{|c|c|c|c|c|c|c|}
\hline \multirow{3}{*}{$\begin{array}{l}\text { Work-schedule } \\
\text { characteristic }\end{array}$} & \multicolumn{6}{|c|}{ Musculoskeletal disorder } \\
\hline & \multicolumn{2}{|l|}{ Neck } & \multicolumn{2}{|c|}{ Shoulder } & \multicolumn{2}{|l|}{ Back } \\
\hline & $\mathrm{OR}$ & $95 \% \mathrm{Cl}$ & OR & $95 \% \mathrm{Cl}$ & $\mathrm{OR}$ & $95 \% \mathrm{Cl}$ \\
\hline \multicolumn{7}{|l|}{ Hours per day by hours per week } \\
\hline$<9$ hours/day, <40/week & 1.00 &.. & 1.00 & .. & 1.00 & .. \\
\hline 9-11.5 hours/day, $\leq 40 /$ week & 1.32 & $0.82-2.11$ & 1.47 & $0.89-2.42$ & 1.10 & $0.69-1.74$ \\
\hline$\geq 12$ hours/day, $<40 /$ week & 1.08 & $0.70-1.67$ & 1.04 & $0.65-1.66$ & 1.25 & $0.84-1.85$ \\
\hline$\geq 12$ hours/day, $\geq 40$ /week & 2.30 & $1.03-5.11$ & 2.48 & $1.07-5.77$ & 2.67 & $1.26-5.66$ \\
\hline \multicolumn{7}{|l|}{ Shift worked by weekends per month } \\
\hline Day shift, with 0-1 wk weekends & 1.00 & .. & 1.00 & .. & 1.00 & .. \\
\hline Day shift, with $\geq 2$ weekends & 1.19 & $0.74-1.91$ & 0.94 & $0.55-1.60$ & 1.61 & $1.04-2.50$ \\
\hline Other shift, with 0-1 weekends & 1.02 & $0.53-1.95$ & 1.34 & $0.70-2.56$ & 1.19 & $0.64-2.19$ \\
\hline Other shift, with $\geq 2$ weekends & 1.43 & $0.94-2.18$ & 1.52 & $0.98-2.38$ & 2.08 & $1.35-2.96$ \\
\hline
\end{tabular}

hours/week) elevated the odds ratios for musculoskeletal disorders of the neck (OR 2.30, 95\% CI 1.03-5.11), a shoulder (OR 2.48, 95\% CI 1.07-5.77), and the back (OR
2.67, 95\% CI 1.26-5.66) (table 5). Neither working $\geq 12$ hours per day or $\geq 40$ hours per week in and of itself increased the risk of reported musculoskeletal disorders. 


\section{Discussion}

This study is one of the first to explore the relationship between a combination of work-schedule characteristics and reported musculoskeletal disorders among nurses. Nurses meeting the case definition for musculoskeletal disorders of the neck, shoulder, or back reported significantly higher mean scores for all the demanding workschedule characteristics combined when compared with asymptomatic nurses. The most problematic of the schedule combinations was working long hours and working off shifts. Working $\geq 12$ hours per day in combination with $\geq 40$ hours per week was associated with a statistically significant increase in the odds ratios of reported musculoskeletal disorders in all three body sites (OR ranging from 2.30 to 2.67). For nurses working a combination of "off shifts", defined as "other than day shift", and 2 to 4 weekends per month, the odds ratio for a reported musculoskeletal disorder ranged from 1.43 to 2.08 .

The work-schedule characteristic index was significantly associated with musculoskeletal disorders although this finding was somewhat diminished when exposures to psychological and physical job demands were taken into account. This result suggests that demanding work schedules may contribute to musculoskeletal disorders both directly and indirectly (through exposure to physical demands or psychological demands or both physical and psychological demands). In a recent review of models of work stress and upper-extremity disorders, four pathways for the influence of work organization on these disorders were described. The models suggested that work organization can influence musculoskeletal disorders by directly affecting ergonomic exposures and biomechanical loads, contributing to stress responses (physiological, psychological, and behavioral) that have an impact on the relationship between ergonomic exposures and musculoskeletal disorders, exerting a direct effect on symptom expression, and intersecting with individual factors that are codeterminants of stress responses and their effect on musculoskeletal disorders (36).

The association of working other shifts and weekends with reported musculoskeletal disorders at all sites suggests that the combination of these two schedule characteristics is of concern. Weekend work by itself was associated with reported musculoskeletal disorders of the back, whereas "other then day shift" by itself was not associated with any musculoskeletal disorder. This finding is noteworthy given the current research emphasis on shifts that do not consider the impact of weekend work. Lower staffing ratios are often maintained on weekends, as well as on off shifts, even though job demands may remain unchanged when compared with the times when more help is available. Staffing levels have been shown to be risk factors for musculoskeletal disorders of the back, and this finding suggests that such a work schedule may need modification (26). Our findings that reported musculoskeletal disorders were not associated with longer days ( $>8$ hours) among those working $\leq 40$ hours per week is important. Much of the research examining the impact of long workdays to date has focused on shift length alone, rather than on the combined impact of long shifts with $>40$-hour workweeks.

Some studies have examined the health consequences of 8-hour and 12-hour workshifts on fatigue, sleep, performance $(28,37,38)$, low alertness-related outcomes $(39,40)$, and injury risk (41-43) among industrial workers. The methods used have varied, with equivocal findings $(44,45)$. Studies of nurses working 8-hour and 12-hour shifts have focused on work performance and quality of care (46-48) and have found both benefits for and limitations to the 12-hour workshift.

A major limitation of our study is its cross-sectional design, which prevented us from interpreting the temporal relationship among the variables. By definition, this cross-sectional study was limited to the current workforce so that nurses who had left nursing due to musculoskeletal disorders or other health conditions were not included. The absence of these nurses from the study population could have led to an underestimate of the prevalence of reported musculoskeletal disorders and the association of schedules with reported musculoskeletal disorders. Longitudinal studies, needed to estimate further the prevalence of musculoskeletal disorders and clarify the relation of reported past-year schedules to the onset of reported musculoskeletal disorders, are now in progress.

A second limitation of our study was its exclusive use of self-reported data. We attempted to reduce recall bias by limiting the recall period for reported musculoskeletal disorders to the past year and by using a threshold definition for a reported case. There is evidence that nurses, as a population, provide valid and reproducible data on risk factors and health outcomes when surveyed (50-52). Nonetheless, as there was no validation of a reported musculoskeletal disorder from observation or examination, the findings need to be interpreted with caution.

This survey of over 1000 nurses indicates that nurses work long hours, take few to no breaks during the course of the workday, and experience reported musculoskeletal disorders of the neck, shoulders, and back. A combination of demanding work-schedule characteristics increased the odds ratios of reported musculoskeletal disorders of the neck, shoulders, and back in this population. Working weekend off shifts and working long hours per day and per week emerged as concerns in 
relation to musculoskeletal disorders. These findings are particularly critical given the current and projected shortage of registered nurses and the increasing demands for them to work more and longer hours to cover staffing gaps. Research addressing long hours of work should focus on the combined impact of various work-schedule characteristics, to estimate more adequately the health consequences of extended work schedules. Intervention studies designed to evaluate the impact of workload and hours of work on nurses' injuries and illnesses are needed. The prevention of musculoskeletal disorders among nurses through more healthful scheduling will require organizational approaches. An increase in staff during off-shifts and weekends and a limit on hours worked per week for longer shifts may be indicated, as these scheduling characteristics were associated with the greatest odds ratios of reported musculoskeletal disorders in the neck, a shoulder, and the back.

\section{Acknowledgments}

We would like to express our appreciation to Dr Steven L Sauter for his thoughtful review of this manuscript. We would also like to thank Karen Nielsen and Sumalee Lirtmunliukaporn for their assistance with preparing the manuscript.

This study was funded by the Centers for Disease Control and Prevention, National Institute for Occupational Safety and Health (RO1 OH03702), in the United States.

\section{References}

1. Shindul-Rothschild J, Berry D, Long-Middleton E. Where have all the nurses gone? Final results of our patient care survey. Am J Nurs 1996;11:25-39.

2. Norrish R, Rundell T. Hospital restructuring and the work of registered nurses. Millbank Q 2001;79(1):55-79.

3. Sochalski J, Estabrooks C, Humphrey C. Nurse staffing and patient outcomes: evolution of an international study. Can J Nurs Res 1999;31(3):69-88.

4. Bureau of Labor Statistics. Occupational outlook handbook. Retrieved May 2, 2001 from World Wide Web: http:// www.bls.gov/iif/oshwc/osh/os/ostb0989.pdf .

5. Allen A. On-the-job injury: a costly problem. J Post Anesth Nurs 1990;5(5):367-8.

6. Brulin C, Gerdle B, Granlund B, Hoog J, Knutson A, Sundelin G. Physical and psychosocial work-related risk factors associated with musculoskeletal symptoms among home care personnel. Scand J Caring Sci 1998;12(2):104-10.

7. Collins JW, Owen BD. NIOSH research initiatives to prevent back injuries to nursing assistants, aides, and orderlies in nursing homes. Am J Ind Med 1996;29(4):421-4.

8. Marras WS, Davis KG, Kirking BC, Bertsche PK. A comprehensive analysis of low-back disorder risk and spinal loading during the transferring and repositioning of patients using different techniques. Ergonomics 1999;42(7):904-26.

9. Sosnowitz BG, Hriceniak JP. Neonatal intensive care units can be hazardous to nurses' health. J Perinatol 1988;8(3): 253-7.

10. Fredrickson K, Alfredson L, Koster M, Thorbjornsson C, Toomingas A, Torgen M, et al. Risk factors for neck and upper limb disorders: results from 24 years of follow up. Occup Environ Med 1999;56(1):59-66.

11. Trinkoff A, Storr C, Lipscomb J. Physically demanding work and inadequate sleep, pain medication use, and absenteeism in registered nurses. J Ooccup Environ Med 2001;43(4):35563.

12. Hui L, Ng G, Yeung S, Hui-Chan C. Evaluation of physiological work demands and low back neuromuscular fatigue on nurses working in geriatric wards. Appl Ergon 2001; 32(5):479-83.

13. Kurumatani N, Koda S, Nakagiri S, Hisashige A, Sakai K, Saito Y, et al. The effects of frequently rotating shiftwork on sleep and the family life of hospital nurses. Ergonomics 1994; 37(6):995-1007.

14. Gold D, Rogacz S, Bock N, Tosteson T, Baun T, Czeisler C. Rotating shift work, sleep, and accidents related to sleepiness in hospital nurses. Am J Public Health 1992;82(7):1011-4.

15. Corey-Lisle P, Tarzian AJ, Cohen MZ, Trinkoff AM. Healthcare reform: its effects on nurses. J Nurs Adm 1999;29(3):307.

16. Gordon N, Cleary P, Parker C, Czeisler C. The prevalence and health impact of shiftwork. Am J Public Health 1986; 76(10):1225-8.

17. Parkes KR. Shiftwork, job type, and the work environment as joint predictors of health-related outcomes. J Occup Health Psychol 1999;4(3):256-68.

18. Colligan MJ, Frockt IJ, Tasto DL. Frequency of sickness absence and worksite clinic visits among nurses as a function of shift. J Environ Pathol Toxicol 1979;2(5):135-48.

19. Sawyer RG, Tribble CG, Newberg DS, Pruett TL, Minasi JS. Intern call schedules and their relationship to sleep, operating room participation, stress, and satisfaction. Surgery 1999; 126(2):337-42.

20. Orton DI, Gruzelier JH. Adverse changes in mood and cognitive performance of house officers after night duty. BMJ 1989;298(6665):21-3.

21. Åkerstedt T, Knutsson A, Alfredsson L, Theorell T. Shift work and cardiovascular disease. Scand J Work Environ Health 1984;10(6):409-14.

22. Waersted M, Westgaard RH. Working hours as a risk factor in the development of musculoskeletal complaints. Ergonomics 1991;34(3):265-76.

23. Larese F, Fiorito A. Musculoskeletal disorders in hospital nurses: a comparison between two hospitals. Ergonomics 1994;37(7):1205-11.

24. Engkvist I-L, Hagberg M, Wigaeus-Hjelm E, Menckel E, Ekenvall L, PSOSA study group. The accident process preceding overexertion back injuries in nursing personnel. Scand J Work Environ Health 1998;24(5):367-75.

25. Engels JA, van der Gulden JW, Senden TF, van't Hof B. Work related risk factors for musculoskeletal complaints in the nursing profession: results of a questionnaire survey. Occup Environ Med 1996;53(9):636-41.

26. Wunderlich GS, Sloan FA, Davis CK. Nursing staff in hospitals and nursing homes. Washington (DC): Institute of Medicine, National Academy Press, 1996.

27. Takahashi M, Fukuda H, Miki K, Haratani T, Kurabayashi L, 
Hisanaga N, et al. Shift work related problems in 16-h night shift nurses (2): effects on subjective symptoms, physical activity, heart rate, and sleep. Ind Health 1999;37(2):228-36.

28. Rosa R, Bonnet M, Cole L. Work schedule and task factors in upper-extremity fatigue. Hum Factors 1998;40(1):150-8.

29. Spratley E, Johnson A, Sochalski J, Fritz M, Spencer W. The registered nurse population. March 2000. Washington (DC): US Government Printing Office, 2001. US DHHS [HRSA].

30. Kuorinka I, Jonsson B, Kilborn A, Vinterberg H, BieringSorensen F, Andersson G, et al. Standardised Nordic questionnaires for the analysis of musculoskeletal symptoms. Appl Ergon 1987;18(3):233-7.

31. Bernard B, Sauter S, Fine L, Petersen M, Hales T. Job task and psychosocial risk factors for work-related musculoskeletal disorders among newspaper employees. Scand J Work Environ Health 1994;20(6):417-26.

32. Karasek RA. Job content questionnaire and user's guide. Lowell (MA): University of Massachusetts Lowell, Department of Work Environment, 1985.

33. Karasek RA, Theorell T. Healthy work: stress productivity, and the reconstruction of working life. New York (NY): Basic Books, 1990.

34. Rasanen K, Notkola V, Husman K. Perceived work conditions and work-related symptoms among employed Finns. Soc Sci Med 1997;45(7):1099-110.

35. National Institute for Occupational Safety and Health. Musculoskeletal disorders (MSDs) and workplace factors: a critical review of the epidemiologic evidence for work-related musculoskeletal disorders of the neck, upper extremity and low back. Washington (DC): US Government Printing Office, 1997.

36. Huang G, Feuerstein M, Sauter S. Occupational stress and work-related upper extremity disorders: concepts and models. Am J Ind Med 2002;41:298-314.

37. Axelsson J, Kecklund G, Åkerstedt T, Lowden A. Effects of alternating 8- and 12-hour shifts on sleep, sleepiness, physical effort and performance. Scand J Work Environ Health 1998;24 suppl 3:62-8.

38. Tucker P, Smith L, Macdonald I, Folkard S. The impact of early and late shift changeovers on sleep, health, and wellbeing in 8-12-hour shift systems. J Occup Health Psychol 1998;3(3):265-75.

39. Tucker P, Smith L, Macdonald I, Folkard S. Shift length as a determinant of retrospective on-shift alertness. Scand J Work Environ Health 1998;24 suppl 3:49-54.

40. Budnick LD, Lerman SE, Baker TL, Jones H, Czeisler CA. Sleep and alertness in a 12-hour rotating shift work environ- ment. J Occup Med 1994;36(12):1295-300.

41. Hänecke K, Tiedemann S, Nachreiner F, Grzech-Šukalo H. Accident risk as a function of hour at work and time of day as determined from accident data and exposure models for the German working population. Scand J Work Environ Health 1998;24 suppl 3:43-8.

42. Novak R, Auvil-Novak S. Focus group evaluation of night nurse shiftwork difficulties and coping strategies. Chronobiol Int 1996;13(3):457-63.

43. Lowden A, Kecklund G, Axelsson J, Åkerstedt T. Change from an 8-hour shift to a 12-hour shift, attitudes, sleep, sleepiness and performance. Scand J Work Environ Health 1998;24 suppl 3:69-75.

44. Spurgeon A, Harrington JM, Cooper CL. Health and safety problems associated with long working hours: a review of the current position. Occup Environ Med 1997;54(6):36775.

45. Smith L, Folkard S, Tucker P, Macdonald I. Work shift duration: a review comparing eight hour and 12 hour shift systems. Occup Environ Med 1998;55(4):217-29.

46. Gillespie A, Curzio J. A comparison of a 12-hour and eighthour shift system. Nurs Times 1996;92(39):36-9.

47. Reid N, Robinson G, Todd C. The quantity of nursing care on wards working 8-and 12-hour shifts. Int J Nurs Stud 1993; 30(5):403-13.

48. Todd C, Reid N, Robinson G. The quality of nursing care on wards working eight and twelve hour shifts: a repeated measures study using the MONITOR index of quality of care. Int J Nurs Stud 1989;26(4):359-68.

49. Ekberg K, Karlsson M, Axelson O, Malm P. Cross-sectional study of risk factors for symptoms in the neck and shoulder area. Ergonomics 1995;38(5):971-80.

50. Colditz GA, Martin P, Stampfer MJ, Willett WC, Sampson L, Rosner B, et al. Validation of questionnaire information on risk factors and disease outcomes in a prospective cohort study of women. Am J Epidemiol 1986;123(5):894-900.

51. Colditz GA, Stampfer MJ, Willett WC, Stason WB, Rosner $\mathrm{B}$, Hennekens $\mathrm{CH}$, et al. Reproducibility and validity of selfreported menopausal status in a prospective cohort study. Am J Epidemiol 1987;126(2):319-25.

52. Giovannucci E, Stampfer MJ, Colditz GA, Manson JE, Rosner BA, Longnecker MP, et al. Recall and selection bias in reporting past alcohol consumption among breast cancer cases. Cancer Causes Control 1993;4(5):441-8.

Received for publication: 20 May 2002 